\title{
Fuzzy and ANFIS Controllers to Improve the Power Quality of Grid Connected PV System with Cascaded Multilevel Inverter
}

\author{
M Rupesh ${ }^{1}$ and Dr. T S Vishwanath ${ }^{2}$ \\ ${ }^{1}$ Research scholar, EE, VTU and Assistant Professor, BVRIT HYDERABAD College of Engineering for Women, Electrical \& \\ Electronics Engineering, Hyderabad, India \\ ${ }^{2}$ Professor, Electronics \& Communication Engineering, Bheemanna Khandre Institute of Technology Bhalki, India
}

*Correspondence: M Rupesh; Email: m.rupesh1@gmail.com

\begin{abstract}
In this paper, A Cascaded Multi level Inverter (CMLI) interconnected with the $10 \mathrm{KW}$ PV System, Boost Converter along with Cascaded Feed Forwarded Neural Network (CFFNN) MPPT Controller is proposed to improve the Power Quality (PQ) for Linear, Non-linear and unbalanced loading conditions and minimize the total Harmonic Distortion (THD). The CMLI Consists of Novel type 9-Level Inverter with Reduced number of switches, and is connected to Bridged type inverter as cascaded, to get the required amount of Output voltage which can be used for grid integration. For controlling the inverter the Current controller is much required to control the current and to synchronize the Phase lock loop (PLL) is important. Here a new Adoptive Neuro Fuzzy Interface System (ANFIS) Control tuned with PI Controller is used to advance the performance of the power quality of the system under various loading conditions and undesired oscillations and THD can be improved compared with Conventional PI Controller and Fuzzy-PI Controller, Load voltage and current waveforms are analyzed under IEEE 519. The system is developed in the MATLAB environment to check the dynamic PV performance with MPPT controller and the results are found satisfactory.
\end{abstract}

Keywords: PI, Fuzzy, ANFIS, Grid Synchronization, PV, MPPT, CFFNN, Power Quality.

ARTICLE INFORMATION
Author(s): M Rupesh and Dr. T S Vishwanath
Received: Nov 05, 2021; Accepted: Jan 05, 2022; Published: Jan 30, 2022;
e-ISSN: 2347-470X;
Paper Id: IJEER-090401;
Citation: doi.org/10.37391/IJEER.0904011
Webpage-link:
https://ijeer.forexjournal.co.in/archive/volume-9/ijeer-090401.html

\section{INTRODUCTION}

The Renewable Power Generation at Distribution side is most required part in the power sector to reach the increased power demand, because maximum contribution of whole world depends on conventional energy sources like Coal, Oil and Fossil fuels which may exhausted in coming future, if still depends. Hence the PV, Wind and other Renewable energy sources plays major role to meet the demand. Among all alternative power generations, the PV System is predominating even it have challenges like obtaining maximum power, conversion of DC Power into AC and Synchronization.

The above problems can be rectified by introducing the MPPT Controllers and Inverter. Here the inverter uses the current controller and PLL for the power transfer and synchronization respectively.

The literature discusses the idea presented in this paper are the large data analysis and Modelling of PV system was carried out in[1] [2][3][4]. The DC converter topologies are discussed in [5][6], Various MPPT Controllers are discussed in [7][8][9], the converted power from the boost converter is integrated with the grid with the help inverter, the design of inverters are discussed in [10][11][12], various control strategies for inverter control are discussed in [13][14][15], the fuzzy control technology is discussed in [16].

The suggested inverter's triggering pointers are produced using a unipolar variation method, which generates the lowest total harmonic distortion (THD) mutually in production voltage and current. A 1-phase 9-level inverter is used to describe the proposed inverter topology. MATLAB/Simulink is used to model the topology. There is also a comparison of the suggested and conventional topologies. This article presents a new extended idea for lowering the amount of Control switches, diodes, \& dc power supply in an existing CMLI architecture. To validate the anticipated topologies, extensive modelling analysis are performed. The results can explain that the suggested methodology can reduce the number of devices in current topologies though retaining their concert.

This paper proposes a novel two-stage CSDMLI architecture for medium-voltage alternative energy integration. A fuzzy and Adaptive Neuro fuzzy Interface system with PI Control techniques may be utilized to resolve concerns about dc source variations in multilayer inverters used for alternative energy integration. The use of renewable and alternative energy sources may be maximized using these advanced network architectures. For example, linking two or more micro grids allows for standby sharing, voltage and frequency support, and finally boosts the complete dependability \& flexibility of connected micro-grids. 


\section{MODELLING OF PV SYSTEM}

Figure 1 depicts the solar cell as a dependent current source with additional series and parallel resistors linked to a diode. It's worth mentioning that in the non-appearance of solar light, the PV cell acts as a load and generates no power[17]. The quantity of sunlight that falls on the PV cell (photo-current) determines the actual current from the current source (PV cell) (Fig 1) Voltage in an open circuit.

The voltage loss across the diode will affect the PV cell voltage generation.

$$
V=\left(\frac{N K T}{Q}\right) \ln \frac{I_{L}-I_{o}}{I_{\circ}}+1
$$

Where

PV Cell Open circuited Voltage $=\mathrm{V}$

$\mathrm{N}$ stands for the diode constant 1.50

Boltz constant $\mathrm{K}=(1.381 \times 10-23 \mathrm{JK}-1)$

$\mathrm{T}=$ Temperature in kelvin

Q stands for "elementary charge" (1.602 x 10-19 Coulomb)

Io is the Maximum current of a diode (A)

The Generated Current by light (Radiation)

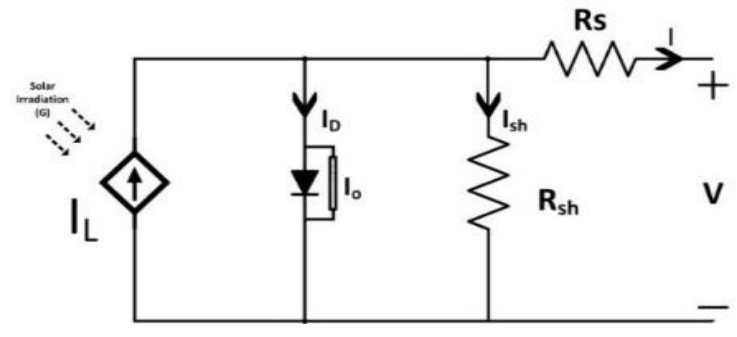

Figure 1: The Equivalent PV cell Circuit

$$
\mathrm{I}_{\mathrm{L}}=\left(\frac{\mathrm{G}}{\mathrm{G}_{\mathrm{ref}}}\right) *\left(\mathrm{I}_{\mathrm{L} \text { ref }}+\propto_{I s c}\left(\mathrm{~T}_{\mathrm{C}}-\mathrm{T}_{\mathrm{C} \text { ref }}\right)\right)
$$

Where

$\mathrm{G}=$ irradiation instantaneous $(\mathrm{W} / \mathrm{m} 2)$

$\mathrm{G}_{\text {ref }}=$ standard Condition with reference irradiation 1000 Watts per square meter

$\mathrm{I}_{\text {Lref }}$ denotes a reference. Under normal circumstances, photoelectric current $0.15 \mathrm{~A}$

Instant temperature $\mathrm{T}_{\mathrm{C}}$.

$\mathrm{T}_{\text {Cref }}$ stands Model temp at $298.0 \mathrm{~K}$

$\alpha_{\text {ISC }}$ stands SC current temp co-efficient $(\mathrm{A} / \mathrm{K})=0.0065 \mathrm{AK}-1$

$\mathrm{I}_{\mathrm{L}}=$ Current Generated by the Light $=\mathrm{I}_{\mathrm{ph}}(\mathrm{A})$

Reverse saturation current

$$
\begin{aligned}
& \text { Io }=I_{o r}\left(\frac{T_{c}}{T_{\text {ref }}}\right)^{3} e^{\frac{(\mathrm{Q} * \mathrm{Eg})}{(\mathrm{K} * \mathrm{~N}) *\left[\left(\frac{1}{\mathrm{Tcref}}\right)-\left(\frac{1}{\mathrm{Tc}}\right)\right]}} \\
& I_{\text {or }}=\frac{I_{\text {sen }}}{e^{\left(\frac{V_{\text {ocn }}}{N * V_{\text {tn }}}\right)}}
\end{aligned}
$$

Where

Io = Current Capacity in Reverse

Current Capacity $=\mathrm{I}_{\text {or }}$

$\mathrm{E}_{\mathrm{g}}$ is the band gap of a silicon diode, which is $1.10 \mathrm{eV}$.

Current $\mathrm{SC}\left(\mathrm{I}_{\mathrm{sh}}=\mathrm{I}_{\mathrm{L}}\right)$
International Journal of Electrical and Electronics Research (IJEER)

Research Article | Volume 9, Issue 4 | Pages 89-95 | e-ISSN: 2347-470X

Under saturation current (SC) circumstances, the maximum current generated by a cell: Volt $=0.00 \mathrm{~V}$

$$
\mathrm{I}_{\mathrm{sh}}=\left(\mathrm{I}_{\mathrm{L}}-\mathrm{I}_{0}\right) *\left(\mathrm{e}^{\frac{\mathrm{eV}}{\mathrm{KT}}}-1\right) \mathrm{A}
$$

\section{DESIGN AND SIMULATION OF CMLI AND GRID INTEGRATION OF PV SYSTEM}

The CMLI seems to be well for connecting green technologies to the grid to enhance overall power quality and reliability. To lower THD for both the current and voltage waveforms, the proposed CMLI was designed using a minimal number of power semiconductors devices. As shown in Figure 2, five MOSFET medium voltage switches are active, each having four PV models connected to it. The staircase modulation mechanism is used to originate pulses in the described multilayer inverter. The H-bridge would be used to design the recommended multilevel inverter in 2 steps, DCDC and DC-AC. Figure 3 illustrates the three-phase output voltage.

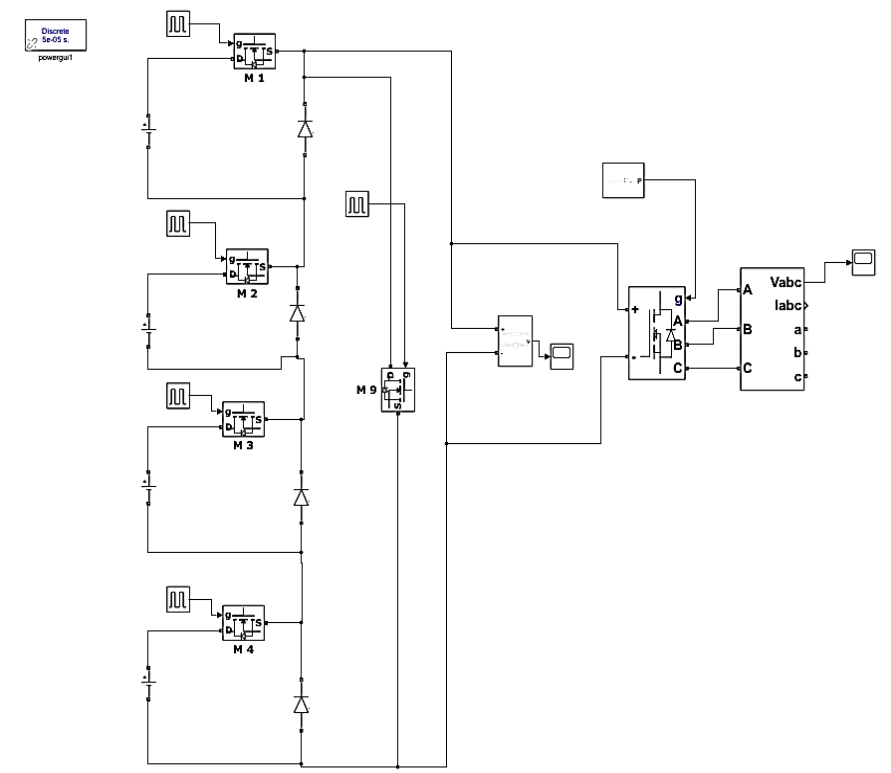

Figure 2: The Novel CMLI topology for grid connected PV system (9Level)

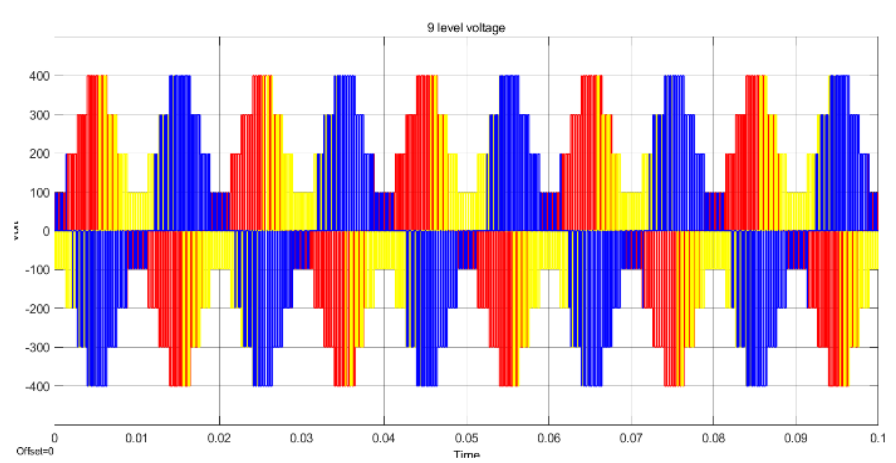

Figure 3: Three phased 9 levels cascade multilevel inverter output voltage waveform 


\section{DESIGN OF MICROGRID AND CONTROL STRATOGIES}

Figure 4 describes the fundamental modelling of a gridIntegrated PV system with a 2-stage 9-level cascaded multilevel inverter, a suggested LC filter, and control structures for a bridged type inverter associated as a cascade to the MLI, along with linear, non-linear, and unbalanced loads.

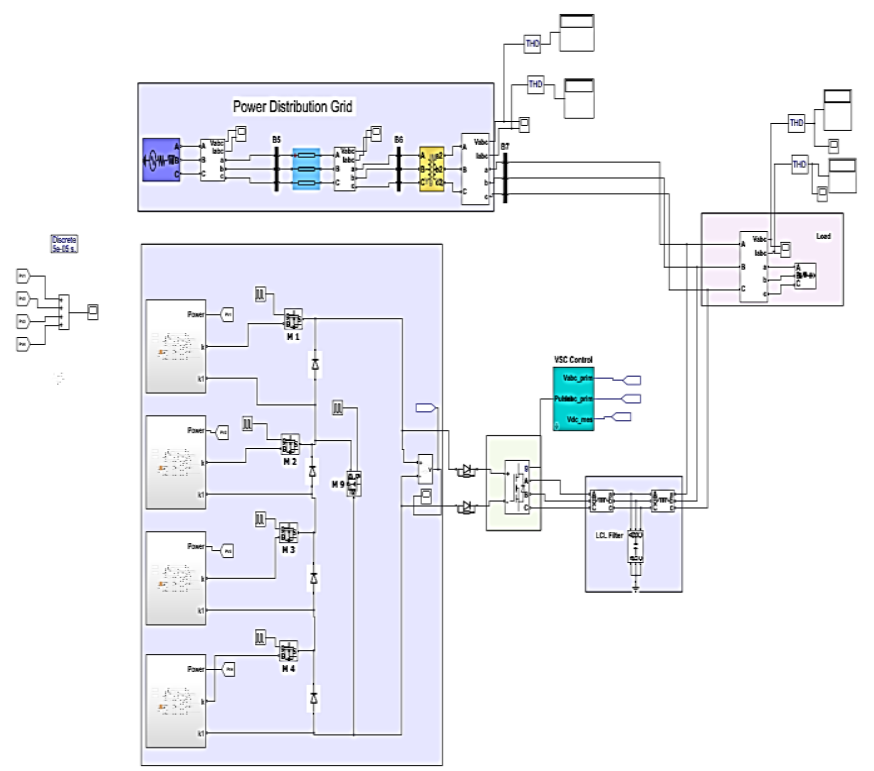

Figure 4: Simulation model of PV system integrating with micro-grid through a proposed multilevel inverter

\subsection{Fuzzy Controller}

The primary benefit of FL mechanism is that it can comprehend inaccuracies in input that don't need scientific modelling, and it also applicable to nonlinear models. Other systems can only grasp Logical 0 or 1 , but our approach can handle any circumstance in the middle.

The fuzzy logic control process is divided into three parts. Fuzzification, inference system (rule basis lookup table), and Defuzzification are the first three steps. Using membership functions, numeric crisp inputs can be transformed into fuzzy terms in fuzzification. The rule basis for the interference system is built using Madani's table technique, Defuzzification is used to convert the FLC results into duty cycle. [18][19].

Figure 5 shows a schematic of a simple fuzzy logic control system.

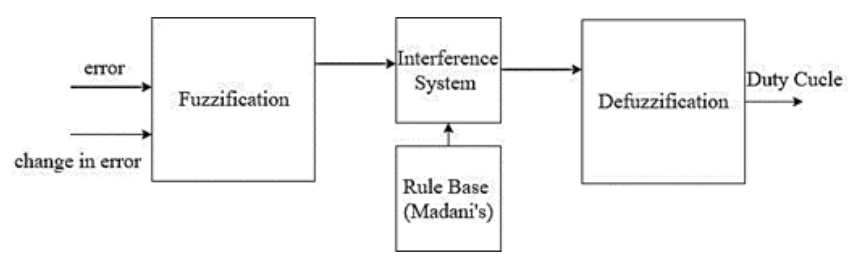

Figure 5: Fuzzy logic control block diagram
In a fuzzy control system, the error and change in errors are computed by taking the voltage and current from the Point of Common Coupling (PCC), the ratio of change in Voltage to change in Current, and minor variations in this value are taken as crisp values for fuzzification.

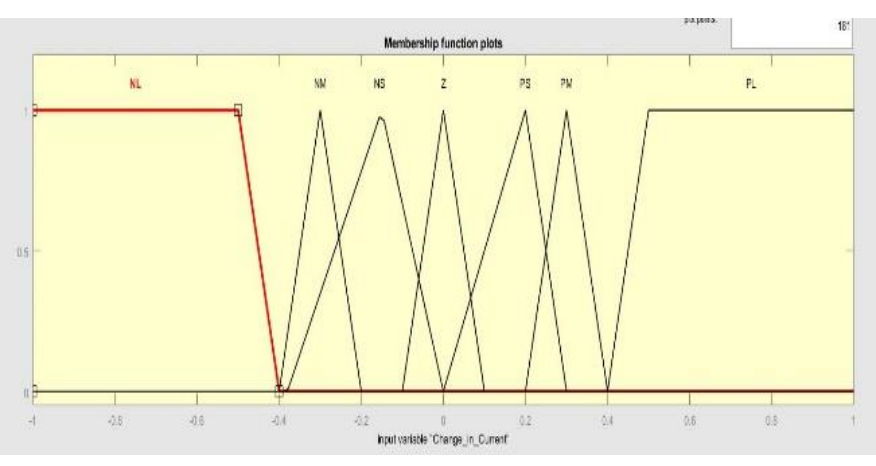

Figure 6: Membership functions for change in current Input

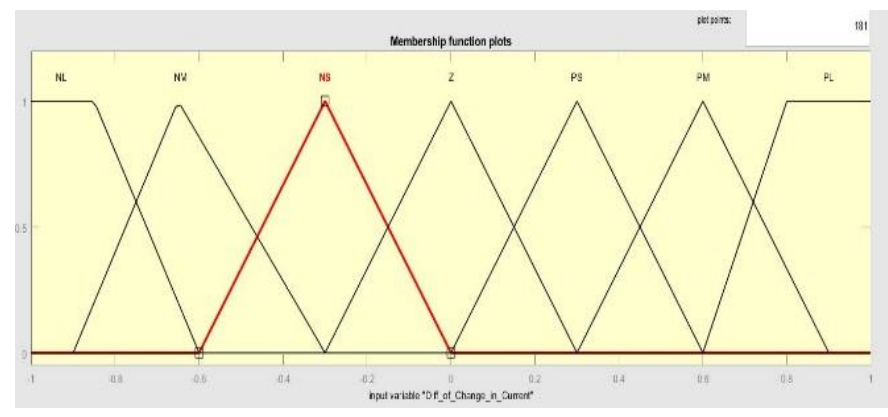

Figure 7: Membership function for Difference of Change in Current

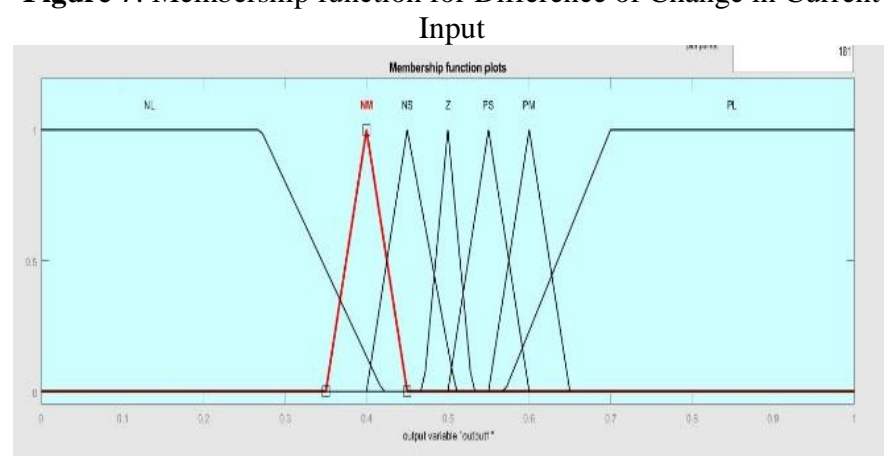

Figure 8: Membership functions for output variables

Figure 6, 7, 8 shows the Input and Output Membership functions for the fuzzy controller in Current Controller topology.

\section{Table 1 : Rule base for fuzzy controller in current} regulator

The Table 1 represents the rule base for fuzzy controller design in current regulator of grid connected PV system along with 9 - level CMLI. 


\begin{tabular}{|c|c|c|c|c|c|c|c|}
\hline \multirow{2}{*}{$\begin{array}{c}\text { Change } \\
\text { in } \\
\text { error }\end{array}$} & \multicolumn{7}{|c|}{ Error } \\
\cline { 2 - 8 } & PL & PM & PS & Z & NS & NM & NL \\
\hline NL & PL & PL & PL & PM & PM & PS & Z \\
\hline NM & PL & PL & PM & PM & PS & Z & ZS \\
\hline NS & PL & PM & PS & Z & NS & NM & NL \\
\hline Z & PL & PM & PS & Z & NS & NM & NL \\
\hline PS & PM & PS & Z & NS & NM & NL & NL \\
\hline PM & PS & Z & NS & NM & NM & NL & NL \\
\hline PL & Z & NS & NM & NM & NL & NL & NL \\
\hline
\end{tabular}

\subsection{Adaptive Neuro Fuzzy Interface System (ANFIS) Controller}

ANFIS is a network that blends the topology of a neural network $(\mathrm{NN})$ with fuzzy logic to create an adaptable network, and it removes some of their drawbacks when used alone. ANFIS's operation resembles that of a feed-forward back propagation network. The calculation of subsequent parameters is done forward, whereas the calculation of premise parameters is done backward. There are two learning methods in the neural component of the system: hybrid learning and back-propagation learning, with the backpropagation approach being the more popular. In the fuzzy portion, only the Sugeno inference system (zero or first order) or the Tsukamoto inference system may be used. ANFIS can handle complicated and nonlinear issues because it mixes neural networks with fuzzy logic. Even if the objectives aren't specified, ANFIS may be able to achieve the best outcome quickly. ANFIS is quicker than NN at reaching the objective. When dealing with a more complicated system with a large amount of data, ANFIS rather than NN would be more beneficial in overcoming the problem's complexity. When compared to other approaches for data training, ANFIS produces outcomes with the least overall error.

ANFIS is a soft computing paradigm that combines neurofuzzy and neural networks to provide complex-level cognitive and low-level processing capacity. Depending on the input and output targets, the ANFIS creates fuzzy interference rules. The NN learning process tunes the fuzzy interference mechanism. The ANFIS has a layered architecture in general, as seen in Figure 9. The input layer, the fuzzification layer, the product layer, the normalisation layer, and the Defuzzification layer are the five layers that make up the system. The nodes are split into adaptive and fixed nodes, with adaptive nodes in squares and fixed nodes in circles. In this approach, the ANFIS inputs are the Point of Common Coupling Voltage and Current, and the output objective is control voltage $\mathrm{V}_{\mathrm{cv}}$. Using these factors, the ANFIS has been creating rules and fine-tuning them.

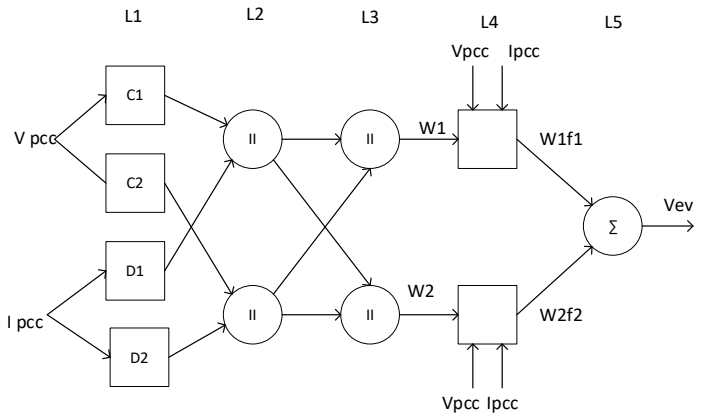

Figure 9: Structure of ANFIS
The Point of Common Coupling voltage Vpce and Current Ipcc, which are specified in the following, are the ANFIS's inputs. Equations (6) and (7) provide a set of rules for a Takagi-Sugeno interference system with two fuzzy components that is first order.

Rule 1: If $\mathrm{Vpcc}$ is $\mathrm{C} 1$ and $\mathrm{THD}$ is $\mathrm{D} 2$ then $\mathrm{f} 1=\mathrm{m} 1 \mathrm{Vpcc}+$ $\mathrm{n} 1 \mathrm{Ipcc}+\mathrm{k} 1$

Rule 2: If $\mathrm{Vpcc}$ is $\mathrm{C} 2$ and $\mathrm{THD}$ is $\mathrm{D} 2$ then $\mathrm{f} 2=\mathrm{m} 2 \mathrm{Vpcc}+$ $\mathrm{n} 2 \mathrm{Ipcc}+\mathrm{k} 2$

Where the linear parameters are $\mathrm{m} 1, \mathrm{~m} 2, \mathrm{n} 1, \mathrm{n} 1, \mathrm{k} 1$ and $\mathrm{k} 2$, and the nonlinear parameters are $\mathrm{C} 1, \mathrm{C} 2, \mathrm{D} 1$ and D2. The ANFIS' fuse rationale is shown in Figure 2.

Activation levels of the fuzzy rules are calculated using $\mathrm{W}=$ $\mathrm{Xi}(\mathrm{a}) \cdot \mathrm{Yi}(\mathrm{b})$,

By multiplying the standardized activation degrees of the rules by the individual output of each rule, which is represented in the following Eq., the output of the model $\mathrm{f}$ is produced in Equation (8)

$f=\frac{\sum \overline{w_{i}} f_{i}}{\sum w_{i}}, \quad i=1,2,3, \ldots \ldots$

Where $\mathrm{W} 1$ is the normalized value, which is the sum of $\mathrm{W} 1$ and $\mathrm{W} 2$.

Table 2: ANFIS Rule base

\begin{tabular}{|l|l|l|l|}
\hline & In2mf1 & In2mf2 & In3mf3 \\
\hline In2mf1 & OPT1mf1 & Out1mf2 & Out1mf3 \\
\hline In2mf2 & OPT1mf4 & Out1mf5 & Out1mf6 \\
\hline In3mf3 & Out1mf7 & Out1mf8 & Out1mf9 \\
\hline
\end{tabular}

\section{RESULTS AND DISCUSSION}

The output power of a photovoltaic system is shown against the MPPT out power waveform in Figure 10. The boost converter final voltage and currents are shown in Figure 11.

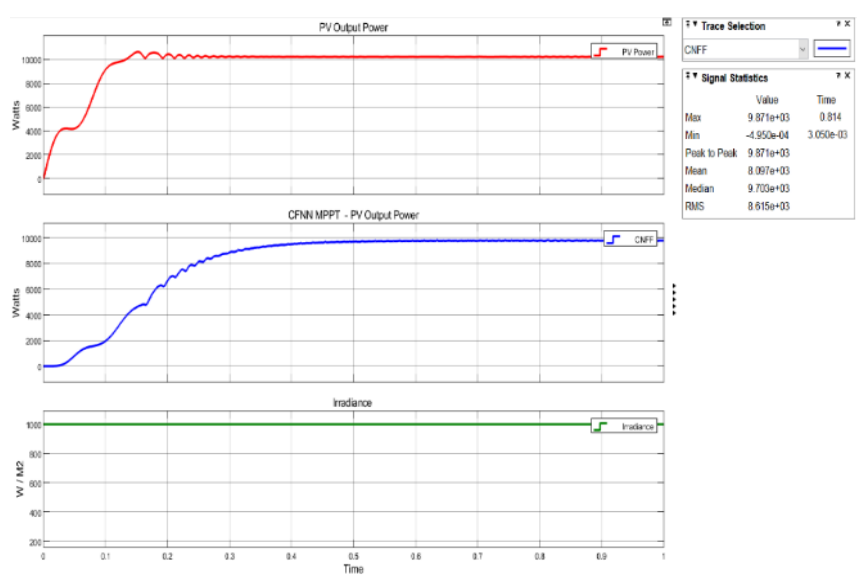

Figure 10: Performance Photovoltaic system with MPPT controller 


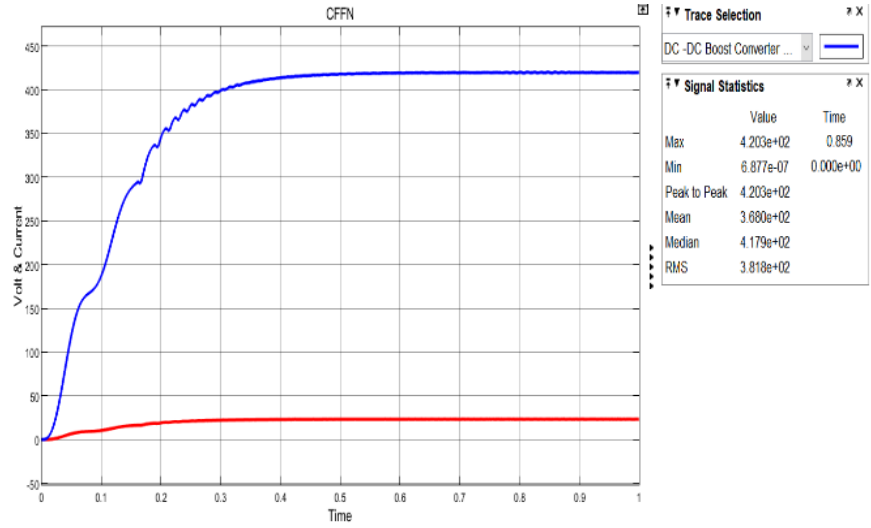

Figure 11: Boost converter output voltage and current

\subsection{Fuzzy Controller}

The Figure 12, 13 and 14 shows the Point of Common Coupling Voltage and Current with non-linear and unbalanced load with a fuzzy controller topology in current regulator, the THD value of Voltage and Current correspondingly. The THD Value of PCC Voltage is $1.57 \%$, and PCC Current is $3.32 \%$.

The Figure 15, 16 and 17 shows the Load Voltage and Current with non-linear and unbalanced load with a fuzzy controller topology in current regulator, the THD value of Voltage and Current respectively. The THD Value of Load Voltage is $1.57 \%$, and Load Current is $3.46 \%$.

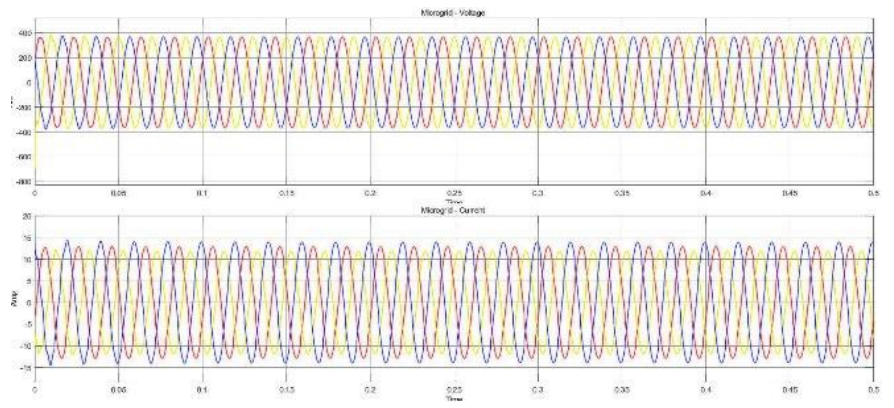

Figure 12: PCC Voltage and Current with Fuzzy Controller

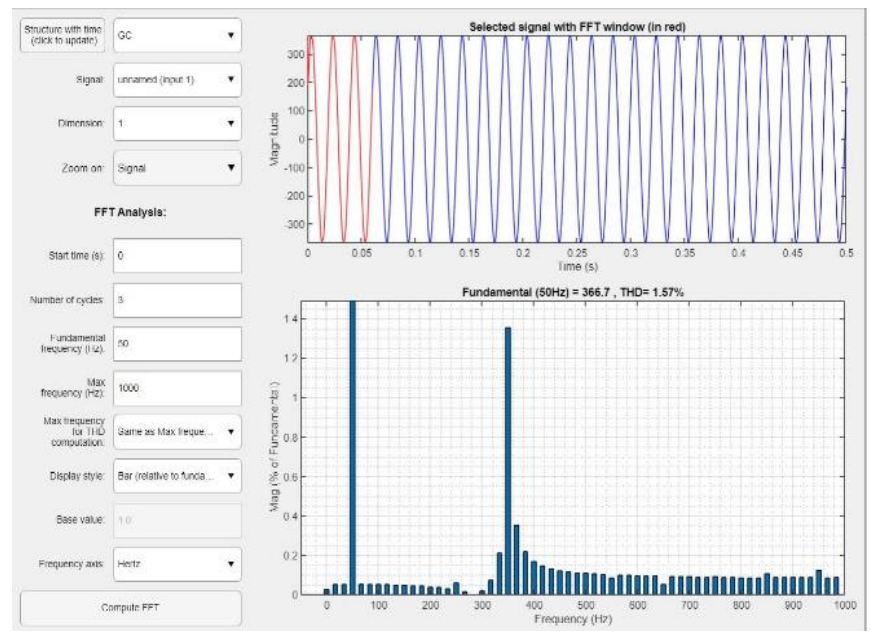

Figure 13: PCC Voltage THD Value with Fuzzy Controller

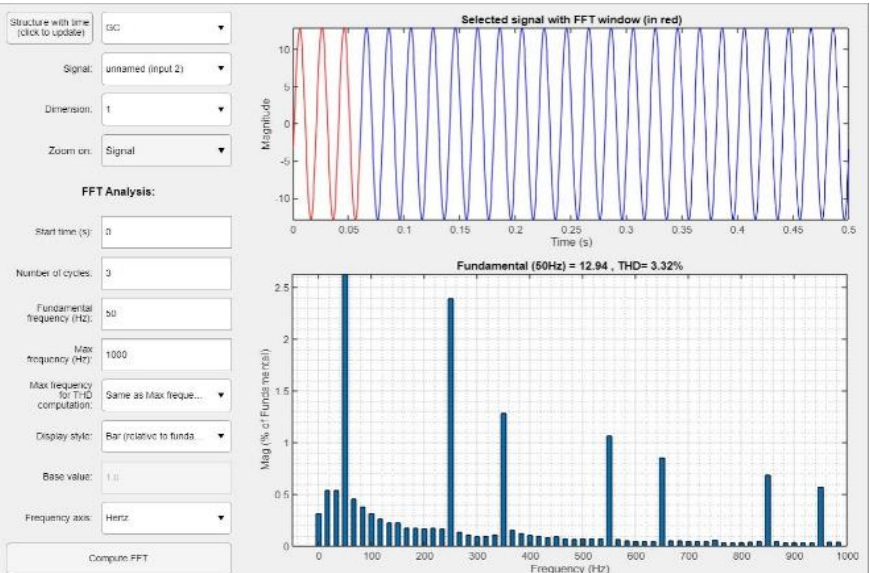

Figure 13: PCC Current THD Value with Fuzzy Controller
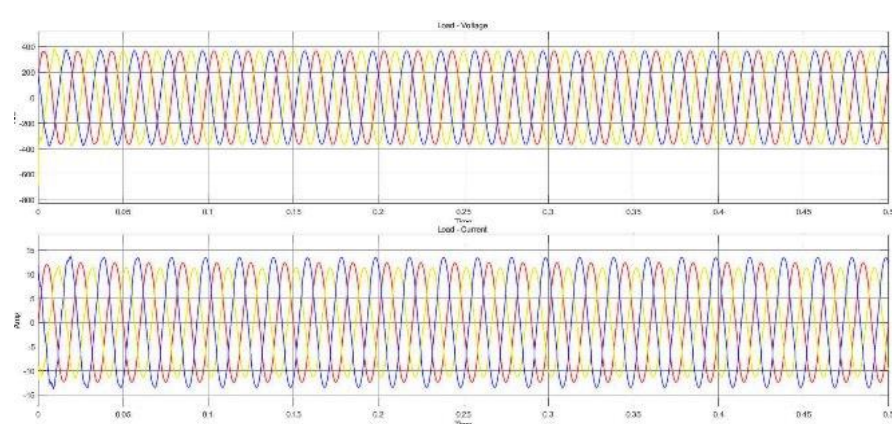

Figure 15: Load Voltage and Current with Fuzzy Controller

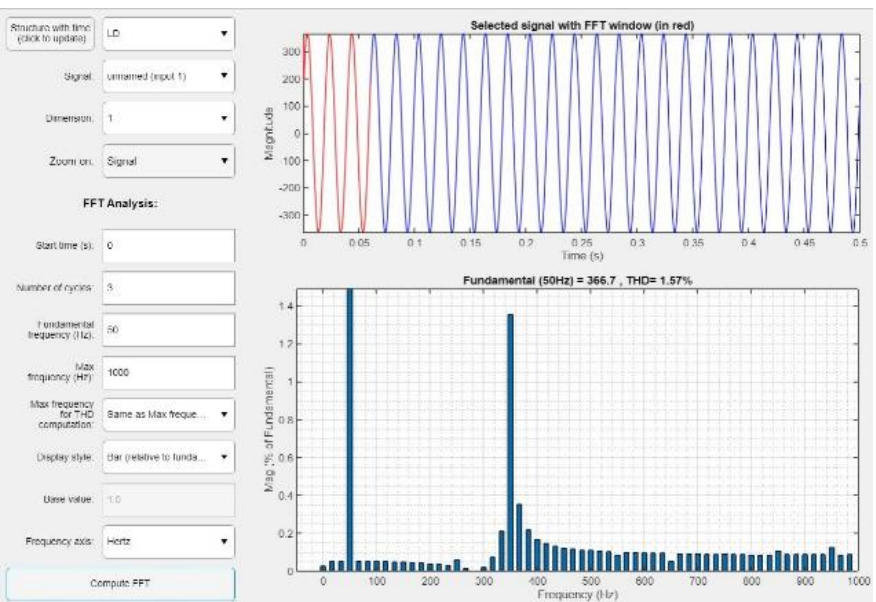

Figure 16: Load Voltage THD Value with Fuzzy Controller

\subsection{ANFIS Controller}

The Figure 17, 18 and 19 shows the Point of Common Coupling Voltage and Current with non-linear and unbalanced load with a ANFIS controller topology in current regulator, the THD value of Voltage and Current correspondingly. The THD Value of PCC Voltage is $1.58 \%$, and PCC Current is $2.77 \%$

The Figure 21, 21 and 22 shows the Load Voltage and Current with non-linear and unbalanced load with a ANFIS controller topology in current regulator, the THD value of Voltage and Current correspondingly. The THD Value of Load Voltage is $1.58 \%$, and Load Current is $2.88 \%$ 

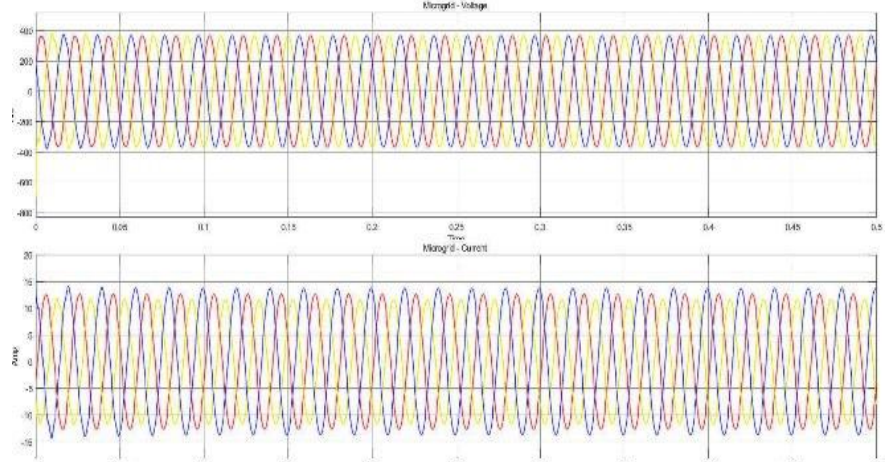

Figure 17: PCC Voltage and Current with ANFIS Controller

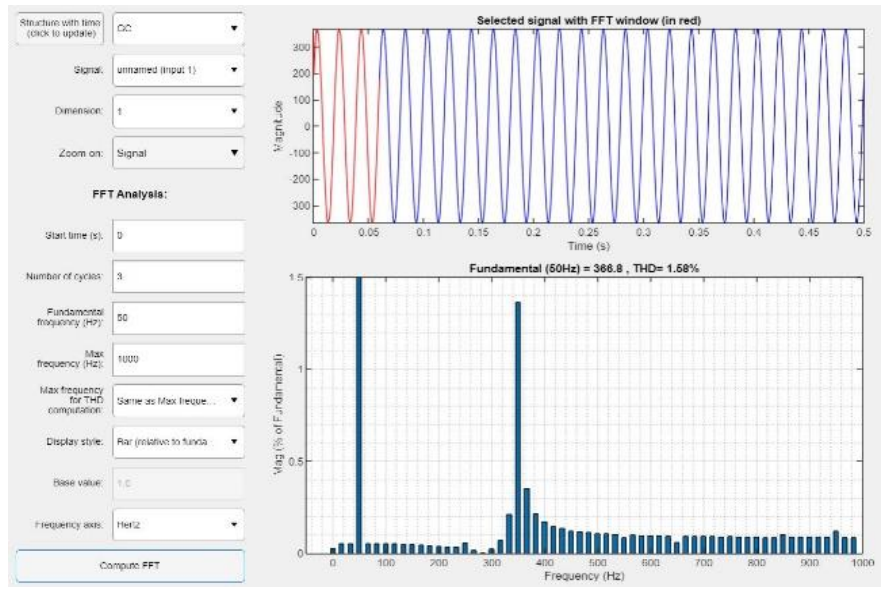

Figure 18: PCC Voltage THD Value with ANFIS Controller

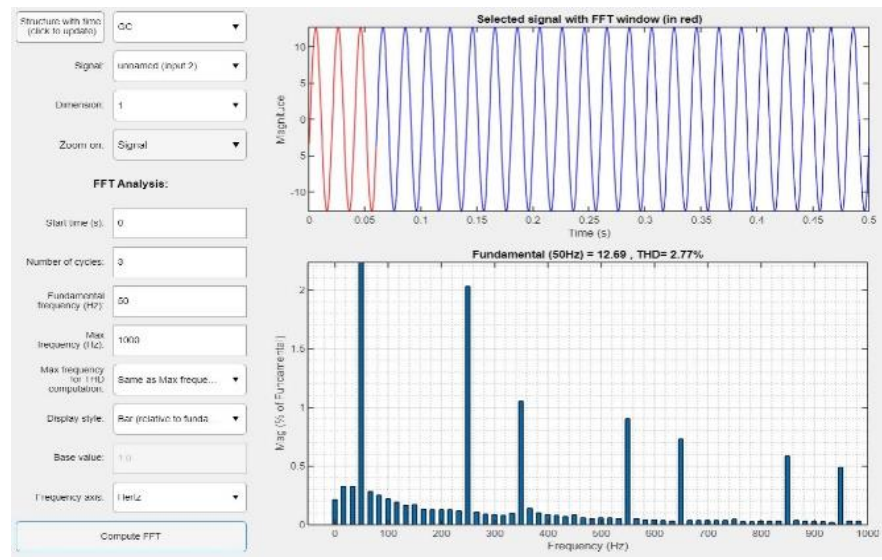

Figure 19: PCC Current THD Value with ANFIS Controller
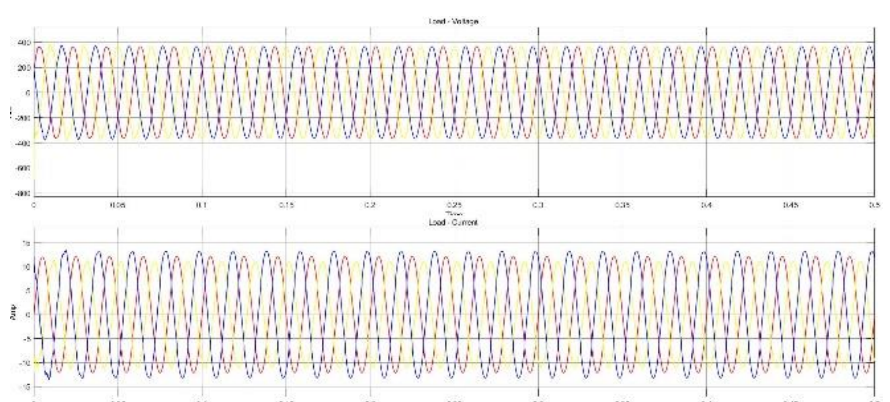

Figure 20: Load Voltage and Current with ANFIS Controller

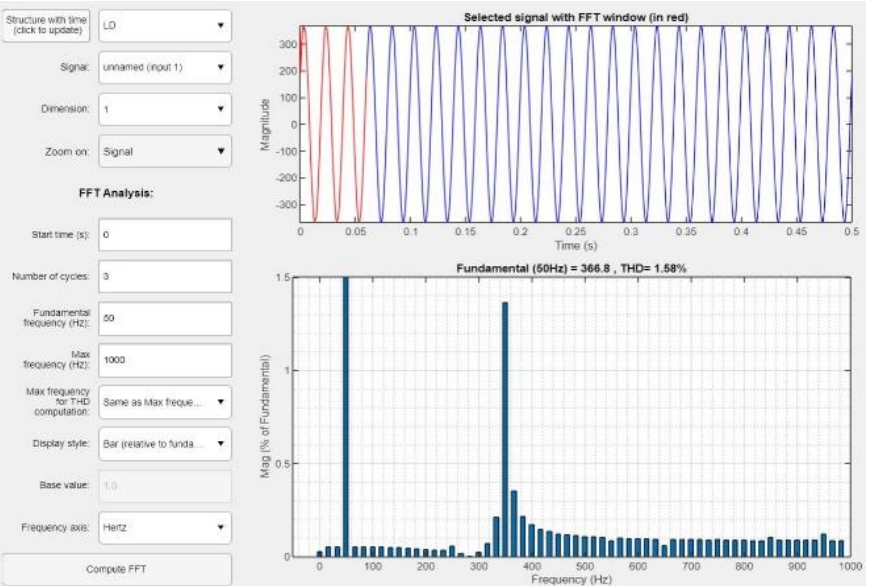

Figure 21: Load Voltage THD Value with ANFIS Controller

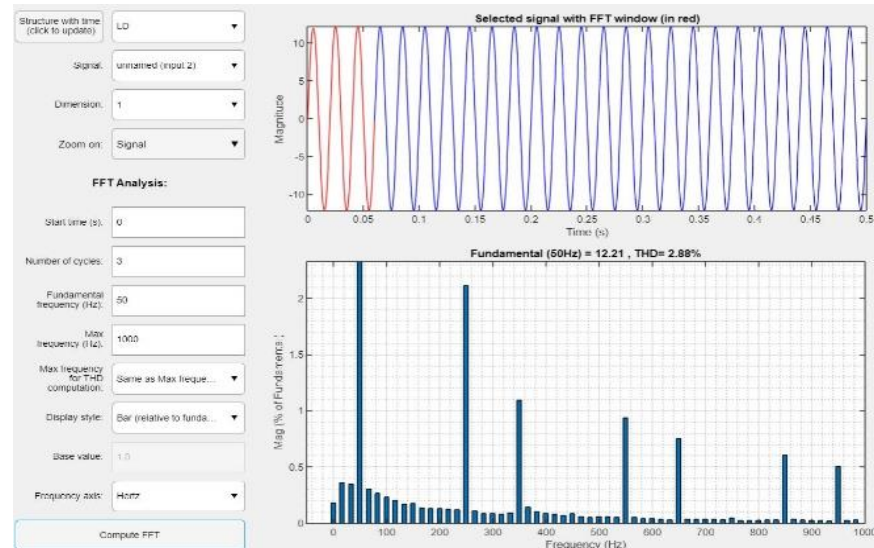

Figure 22: Load Current THD Value with ANFIS Controller

Table 3: THD Values of Voltage and Current for all Controller

\begin{tabular}{|c|l|c|c|c|c|}
\hline \multicolumn{6}{|c|}{ Grid Connected for 3- Cycles, Unbalanced and Nonlinear RL } \\
\hline & & Grid & Grid & Load & Load \\
\hline \multirow{2}{*}{$\begin{array}{c}\text { With PI } \\
\text { Controller }\end{array}$} & $\mathrm{R}$ & $1.57 \%$ & $4.00 \%$ & $1.57 \%$ & $4.15 \%$ \\
\cline { 2 - 6 } & $\mathrm{Y}$ & $3.80 \%$ & $6.21 \%$ & $3.80 \%$ & $6.51 \%$ \\
\cline { 2 - 6 } & $\mathrm{B}$ & $2.25 \%$ & $4.74 \%$ & $2.25 \%$ & $4.91 \%$ \\
\hline \multirow{3}{*}{$\begin{array}{c}\text { With Fuzzy } \\
\text { Controller }\end{array}$} & $\mathrm{R}$ & $1.57 \%$ & $3.32 \%$ & $1.57 \%$ & $3.46 \%$ \\
\cline { 2 - 6 } & $\mathrm{Y}$ & $3.80 \%$ & $5.49 \%$ & $3.80 \%$ & $5.77 \%$ \\
\hline \multirow{2}{*}{$\begin{array}{c}\text { With } \\
\text { ANFIS }\end{array}$} & $\mathrm{B}$ & $2.25 \%$ & $4.26 \%$ & $2.25 \%$ & $4.42 \%$ \\
\cline { 2 - 6 } Controller & $\mathrm{Y}$ & $1.58 \%$ & $2.77 \%$ & $1.58 \%$ & $2.88 \%$ \\
\cline { 2 - 6 } & $\mathrm{B}$ & $2.78 \%$ & $4.87 \%$ & $3.78 \%$ & $5.12 \%$ \\
\hline
\end{tabular}

\section{CONCLUSION}

For the $40 \mathrm{~kW} \mathrm{PV} \mathrm{system,} \mathrm{this} \mathrm{article} \mathrm{focused} \mathrm{on}$ modelling the $10 \mathrm{~kW}$ PV system with a novel type reduced switched 9-Level Cascaded Multilevel Inverter and implementing it in MATLAB with two proposed controllers: the Fuzzy Control algorithm and the Adoptive Neuro Fuzzy Interface System Control algorithm. The model was simulated, and the system's performance was evaluated in a variety of scenarios. The integration and performance of photovoltaic 
systems were the subject of the second portion of this study report. Finally, the proposed system was put to the test under a variety of operating conditions, including imbalanced and nonlinearity, and the results are shown in Table 3 . The proposed system's effectiveness, simulation results, and load voltage and current waveforms are analyzed under IEEE 519, and it can be concluded that the Adoptive Neuro Fuzzy Interface System (ANFIS) Control Algorithm gives better THD values for all the operating conditions than the Fuzzy Control algorithm, hence the ANFIS control algorithm can be suggested for improving the Power Quality in various Operating conditions.

\section{CONFLICTS OF INTEREST}

None.

\section{REFERENCES}

[1] M Rupesh, Dr. T S Vishwanath "Comparative analysis of P \& $\mathrm{O}$ and Incremental conductance methods for standalone PV system,” Int. J. Eng. Technol., vol. 7, no. 3.29, pp. 519-529, 2018.

[2] A. Saberian, H. Hizam, M. A. M. Radzi, M. Z. A. Ab Kadir, and M. Mirzaei, "Modelling and prediction of photovoltaic power output using artificial neural networks," Int. J. Photoenergy, vol. 2014, 2014.

[3] H. Tian, F. Mancilla-david, K. Ellis, P. Jenkins, and E. Muljadi, "A Detailed Performance Model for Photovoltaic Systems Preprint," Sol. Energy J., no. July, 2012.

[4] X. H. Nguyen and M. P. Nguyen, "Mathematical modeling of photovoltaic cell/module/arrays with tags in Matlab/Simulink," Environ. Syst. Res., vol. 4, no. 1, p. 24, 2015.

[5] J. M. Enrique, A. J. Barragán, E. Durán, and J. M. Andújar, "Theoretical Assessment of DC/DC Power Converters' Basic Topologies. A Common Static Model," Appl. Sci., vol. 8, no. 1, p. 19, 2017.

[6] R. Arulmurugan and N. S. Vanitha, "Optimal Design of DC to DC Boost Converter with Closed Loop Control PID Mechanism for High Voltage Photovoltaic Application," Int. J. Power Electron. Drive Syst., vol. 2, no. 4, pp. 434-444, 2012.

[7] M. W. Rahman, C. Bathina, V. Karthikeyan, and R. Prasanth, "Comparative analysis of developed incremental conductance (IC) and perturb \& observe (P\&O) MPPT algorithm for photovoltaic applications," Proc. 10th Int. Conf. Intell. Syst. Control. ISCO 2016, no. Ic, 2016.

[8] A. M. Noman, K. E. Addoweesh, and H. M. Mashaly, “A fuzzy logic control method for MPPT of PV systems," IECON 2012 38th Annu. Conf. IEEE Ind. Electron. Soc., no. May 2014, pp. 874-880, 2012.
[9] O. Ezinwanne, F. Zhongwen, and L. Zhijun, "Energy Performance and Cost Comparison of MPPT Techniques for Photovoltaics and other Applications," Energy Procedia, vol. 107, no. September 2016, pp. 297-303, 2017.

[10] F. Chan and H. Calleja, "Reliability: A new approach in design of inverters for PV systems," Int. Power Electron. Congr. ..., 2006.

[11] J. Xu and K. Han, "The single-phase inverter design for photovoltaic system," Proc. - 2016 IEEE Int. Symp. Comput. Consum. Control. IS3C 2016, no. 1, pp. 341-344, 2016.

[12] G. Revana and V. R. Kota, "Simulation and implementation of resonant controller based PV fed cascaded boost-converter three phase five-level inverter system," J. King Saud Univ. - Eng. Sci., vol. 32, no. 7, pp. 411-424, 2020.

[13] I. E. Tashiwa, G. D. Dung, and B. S. Adole, "Review of Multilevel Inverters and Their Control Techniques,” Eur. J. Eng. Res. Sci., vol. 5, no. 6, pp. 659-664, 2020.

[14] M. Sarebanzadeh, M. A. Hosseinzadeh, C. Garcia, E. Babaei, S. Islam, and J. Rodriguez, "Reduced Switch Multilevel Inverter Topologies for Renewable Energy Sources," IEEE Access, vol. 9, no. 3, pp. 120580-120595, 2021.

[15] M. Education, "A Cascaded Multilevel Inverter With Reduced Switch Count Using Modified Sinusoidal Pulse Width Modulation Technique," vol. 12, no. 10, pp. 2175-2180, 2021.

[16] C. Cecati, F. Ciancetta, and P. Siano, "A multilevel inverter for photovoltaic systems with fuzzy logic control," IEEE Trans. Ind. Electron., vol. 57, no. 12, pp. 4115-4125, 2010.

[17] M Rupesh, Dr. T S Vishwanath, Dr. Venkatesh Kumar M, "Cascaded Feed Forward Multilayer Neural Network based MPPT Controller for Improving the Performance of Photovoltaic System," Turkish J. Comput. Math. Educ., vol. 12, no. 10, pp. 7008-7019, 2021.

[18] D. Beriber and A. Talha, "MPPT techniques for PV systems," Int. Conf. Power Eng. Energy Electr. Drives, no. May, pp. 14371442, 2013.

[19] P. Paikray, S. C. Swain, R. Dash, and P. C. Panda, "A review on current control techniques for inverter for three phase grid connected renewable sources," 2017 Innov. Power Adv. Comput. Technol. i-PACT 2017, vol. 2017-January, pp. 1-6, 2017.

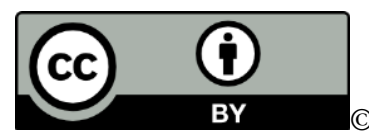

2021 by the M Rupesh and Dr. T S Vishwanath. Submitted for possible open access publication under the terms and conditions of the Creative Commons Attribution (CC BY) license (http://creativecommons.org/licenses/by/4.0/). 